\title{
Gallstone ileus: A rare cause of small intestine obstruction
}

\author{
Francesk Mulita $^{1}{ }^{\circledR} \mid$ Levan Tchabashvili $^{1} \mid$ Dimitrios Bousis $^{2}$ | \\ Dimitrios Kehagias $^{1}$ | Charalampos Kaplanis ${ }^{1}$ | Elias Liolis ${ }^{2}$ | Ioannis Perdikaris $^{1}$ | \\ Fotios Iliopoulos $^{1}$ | Georgios-Ioannis Verras ${ }^{1}$ | Konstantinos Bouchagier ${ }^{1}$
}

${ }^{1}$ Department of General Surgery, General University Hospital of Patras, Patras, Greece

${ }^{2}$ Department of Internal Medicine, General University Hospital of Patras, Patras, Greece

\section{Correspondence}

Francesk Mulita, Resident Surgeon at the Department of Surgery, General

University Hospital of Patras, Achaia, Greece.

Email: oknarfmulita@hotmail.com

Funding information

None

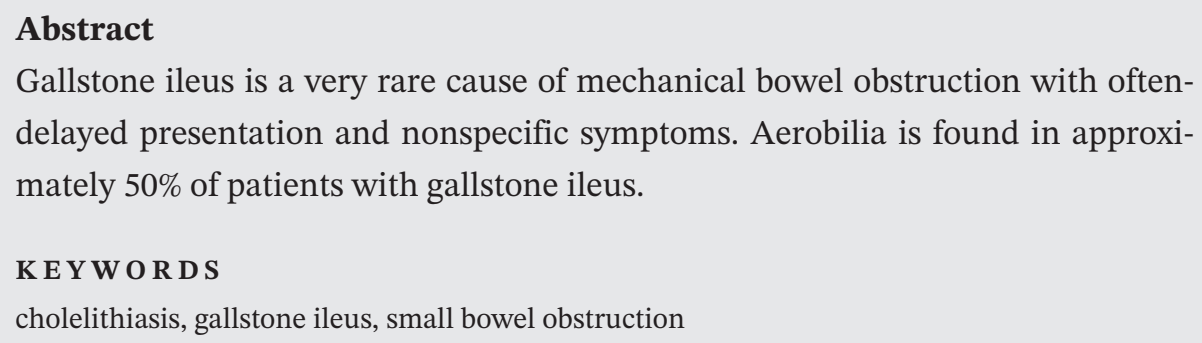

\section{CASE DESCRIPTION}

A 77-year-old woman was admitted to our emergency department (ED) complaining of abdominal distension, vomiting, and nausea. During physical examination, normal bowel sounds were auscultated, and there were no signs of abdominal flatulence or tenderness. Her routine blood tests were normal. However, her $\mathrm{C}$ reactive protein was elevated. Abdominal x-rays revealed dilated small bowel as well as air-fluid levels. A computed tomography (CT) was performed and showed aerobilila and a large $5.1 \mathrm{~cm}$ gallstone lodged in the small intestine. The patient was resuscitated with intravenous fluids and underwent emergency surgery. Intraoperative findings noted small bowel obstruction with the transition point at $70 \mathrm{~cm}$ from the ileocaecal valve caused by a large gallstone obstructing the lumen (Figure 1A). A longitudinal $3 \mathrm{~cm}$ enterotomy was made proximal to the distal gallstone (Figure 1B). The stone was removed, and the enterotomy was closed transversely (Figure 1C, D).

Gallstone ileus develops in less than $0.5 \%$ of patients with cholelithiasis and accounts for less than $5 \%$ of nonstrangulating mechanical small bowel obstructions. Patients have nonspecific symptoms and the diagnosis is often delayed since symptoms may be intermittent and investigations may fail to identify the cause of the obstruction. The majority of reported cases of obstruction demonstrate a gallstone larger than $20 \mathrm{~mm}$ in diameter. ${ }^{1}$ If a clinician has a clinical suspicion of gallstone ileus but the patient has negative radiograph findings, a computed tomography (CT) scan should be performed. Aerobilia is found in approximately $50 \%$ of patients. $^{2}$

\section{CONFLICTS OF INTEREST}

There are no conflicts of interest to declare. 


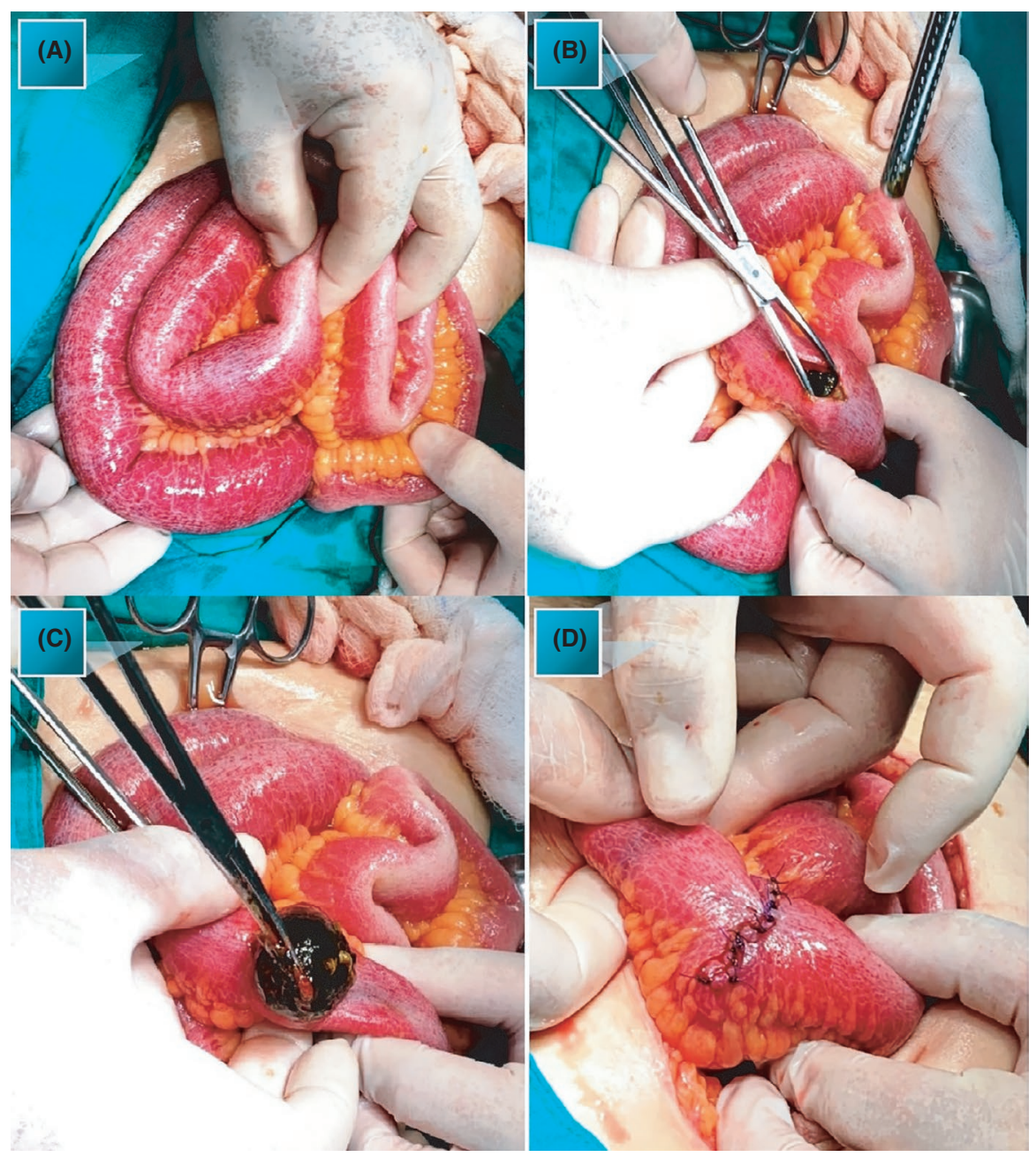

FI G URE 1 (A) Impacted gallstone. (B, C) Small bowel enterotomy for removal of the impacted gallstone. (D) The enterotomy was closed transversely

\section{AUTHOR CONTRIBUTIONS}

FM, DK, LT, G-IV, IP, FI, CK, and EL contributed to the clinical data collection and prepared the case report. FM, LT, and EL contributed to the design of the case report presentation and performed the final revision of the manuscript.

\section{CONSENT}

A written informed consent was obtained from the patient for publication of this case report.

\section{DATA AVAILABILITY STATEMENT}

Data available on request from the authors.

\section{ORCID}

Francesk Mulita (D) https://orcid.org/0000-0001-7198-2628

\section{REFERENCES}

1. Morosin T, De Robles MSB, Putnis S. Gallstone ileus: an unusual cause of intestinal obstruction. Cureus. 2020;12(3):e7284.

2. Salazar-Jiménez MI, Alvarado-Durán J, Fermín-Contreras MR, Rivero-Yáñez F, Lupian-Angulo AI, Herrera-González A. Íleo biliar, revisión del manejo quirúrgico [Gallstone ileus, surgical management review]. Cir Cir. 2019;86(2):182-186. Spanish.

How to cite this article: Mulita F, Tchabashvili L, Bousis D, et al. Gallstone ileus: A rare cause of small intestine obstruction. Clin Case Rep. 2021;9:e04924. https://doi.org/10.1002/ccr3.4924 